\title{
Relevance of duration of transient ischaemic attacks in carotid territory
}

\author{
M J G HARRISON, JOHN MARSHALL, D J THOMAS
}

British Medical fournul, 1978, 1, 1578-1579

\section{Summary and conclusions}

A retrospective review of the clinical and angiographic features of 116 patients who had had one or more transient ischaemic attacks in the carotid territory showed that stenosis of the cervical portion of the internal carotid artery was significantly more prevalent among patients whose attacks had been brief, with full recovery in under one hour. This information may be helpful in selecting patients for angiography.

\section{Introduction}

Transient cerebral ischaemic attacks in the territory of the internal carotid artery are generally believed to be due to thromboemboli. ${ }^{12}$ Angiography discloses evidence of local disease at the origin of the internal carotid artery, a possible source of emboli, in $40-50^{\circ}$ of cases. ${ }^{3+}$ Since angiography carries a small risk of complications and is not always readily available the recognition of features that are likely to be associated with operable lesions in the carotid artery is clearly important. A carotid source of embolic material is suggested both by the joint occurrence of attacks of amaurosis fugax and symptoms related to hemisphere ischaemia and by the presence of a bruit. ${ }^{3}$ We investigated a possible relation between the duration of the transient ischaemic attack (TIA) and the presence of a carotid lesion.

\section{Methods}

We studied 116 patients who had been investigated angiographically after one or more TIAs in the carotid territory. All the patients had had symptoms referable to the cerebral hemisphere; all had described full recovery within 24 hours. The duration of symptoms in each attack was noted, being available from the records in each case. The angiograms were reviewed for evidence of atheromatous changes in the internal carotid artery, both at its origin and intracranially. Any narrowing of the lumen was classed as stenosis. Blood-pressure scores adjusted for age and sex were calculated for each patient. ${ }^{5}$

\section{Results}

Table I shows the age and sex distribution of the patients. The duration of the ischaemic attacks ranged from "a few seconds" to "nearly 24 hours." The patients were divided into three groups according to the duration of symptoms. Sixty-five patients had attacks lasting less than one hour (group 1), 37 had attacks lasting more than one hour (group 2), and 14 had attacks in both categories (group 3). More elderly patients were found in group 1 than group 2,

Institute of Neurology, National Hospital, Queen Square, London WC1N 3BG

M J G HARRISON, DM, FRCP, senior registrar (present appointment: consultant neurologist, Middlesex Hospital, London W1P 7PN)

JOHN MARSHALL, MD, FRCP, professor of clinical neurology

D J THOMAS, MD, MRCP, research fellow
TABLE I-Age and sex distributions of 116 patients with transient ischaemic $\frac{\bar{\omega}}{\widehat{D}}$ attacks

\begin{tabular}{c|c|c|c|}
\hline Age in years & No of men & No of women & Total \\
\hline $40-49$ & 18 & 4 & 22 \\
$50-59$ & 35 & 12 & 47 \\
$60-69$ & 29 & 41 & 0 \\
$70-79$ & 6 & 0 & 6 \\
\hline Total & 88 & 28 & 116 \\
\hline
\end{tabular}

the difference being highly significant (table II). There were no. differences between groups 1 and 2 in the systolic and diastolic blood- $\vec{F}$ pressure scores adjusted for mean age.

Table III shows the angiographic findings in each group. Stenosis $\frac{0}{3}$ of the origin of the internal carotid artery was more common in $\vec{v}$ patients who experienced brief attacks-that is, patients in groups 1 and 3 . When the patients in groups 1 and 3 were combined the likelihood of finding angiographic evidence of carotid narrowing was $\overparen{D}$ five times greater among patients who had had a brief attack $\left(\chi^{2}=10 \cdot 3 ; \overrightarrow{0}\right.$ $\mathrm{P}<0.001)$. On the other hand, carotid occlusion occurred only in patients who had had some long attacks-that is, those in groups 2 . and $3\left(\gamma^{2}=5.84 ; P<0.05\right)$. Lesser degrees of atheromatous change in the cervical carotid were equally prevalent in groups 1 and 2 . Narrowing of the artery was present in $31(48 \%)$ of the patients in group $1 \supset$ but only $3(8 \%)$ of those in group $2\left(x^{2}=16.0 ; \mathrm{P}<0.001\right)$.

TABLE II-Age distribution of patients with short (group 1) and long (group 2) transient ischaemic attacks

\begin{tabular}{|c|c|c|c|c|c|c|c|}
\hline & & & \multicolumn{4}{|c|}{ Age in years } & \multirow{2}{*}{$\begin{array}{c}\text { Total } \\
\text { No of } \\
\text { patients }\end{array}$} \\
\hline & & & $40-49$ & $50-59$ & $60-69$ & $70-79$ & \\
\hline $\begin{array}{l}\text { Group } 1 \\
\text { Group } 2\end{array}$ & 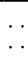 & $\begin{array}{l}. \\
\cdots\end{array}$ & $\begin{array}{r}15 \\
6\end{array}$ & $\begin{array}{l}15 \\
22\end{array}$ & $\begin{array}{r}31 \\
9\end{array}$ & 4 & $\begin{array}{l}65 \\
37\end{array}$ \\
\hline
\end{tabular}

Group $1 v$ group 2 for patients aged 60 and over: $\%^{2}=8.38 ; \mathrm{P}<0.001$.

TABLE III-Angiographic findings in patients with transient ischaemic attacks of $\mathrm{N}$ short duration (group 1), long duration (group 2), and mixed duration (group 3). Figures are numbers (percentages) of patients

\begin{tabular}{|c|c|c|c|c|}
\hline Angiographic finding & $\underset{(\mathrm{n} \quad 65)}{\text { Group } 1}$ & $\underset{(\mathrm{n}=37)}{\text { Group } 2}$ & $\begin{array}{l}\text { Group } 3 \\
(\mathrm{n}=14)\end{array}$ & $\begin{array}{c}\text { Total } \\
(\mathrm{n} \equiv 116)\end{array}$ \\
\hline $\begin{array}{l}\text { Normal } \ldots \\
\text { Internal carotid artery, cervical } \\
\text { part: }\end{array}$ & $14(22)^{*}$ & $16(43)$ & $3(21)$ & $32(28)$ \\
\hline $\begin{array}{l}\text { part: } \\
\text { Atheroma } \quad . .\end{array}$ & $14(22)$ & $9(24)$ & $1 \quad(7)$ & $24(21)$ \\
\hline Stenosis & $24(37)^{* *}$ & $3(8)$ & $6(43)$ & $34(29)$ \\
\hline $\begin{array}{l}\text { Occlusion } \\
\text { Internal carotid artery, siphon: }\end{array}$ & nil* & $3(8)$ & $2(14)$ & \\
\hline $\begin{array}{c}\text { Internal carotid artery, siphon: } \\
\text { Atheroma }\end{array}$ & $1 \quad(2)$ & $2(5)$ & $2(14)$ & $5 \quad(4)$ \\
\hline $\begin{array}{l}\text { Stenosis } \\
\text { Middle cerebral artery. }\end{array}$ & 7 (11) & nil & nil & $7(6)$ \\
\hline $\begin{array}{l}\text { Middle cerebral artery: } \\
\text { Stenosis }\end{array}$ & & & nil & (2) \\
\hline Miscellaneous $\ldots$ & 3 (5) & $4(11)$ & nil & 7 (6) \\
\hline
\end{tabular}

Group $1 v$ group $2:{ }^{*} \mathrm{P}<0.05 ;{ }^{*} \mathrm{P}<0.01$

\section{Discussion}

Our results show that brief ischaemic attacks were more often associated with carotid stenosis than were longer-lasting attacks. Narrowing of the internal carotid artery was five times more common in patients whose hemisphere TIAs lasted less than 
one hour. Stenotic lesions in the carotid artery were also found more often after short episodes in the study of Pessin et al. ${ }^{6}$ This relation may reflect the small size and friability of embolic material arising on a stenosed carotid lesion. ${ }^{7}$

We found that short attacks were more common in patients over 60 . Only $8^{\circ}{ }_{0}$ of patients with attacks lasting over one hour had carotid stenosis. This suggests that disease of the neck vessels is often not the cause of such episodes. A more likely explanation for these longer attacks is that they are the result of embolism from the heart or aorta. ${ }^{*}$ Their longer duration may reflect the slower restoration of flow to a vessel temporarily obstructed by material arising in the heart and differing in constitution from the platelet fibrin embolus that arises on an atheromatous carotid lesion.

The presence of a bruit is known to increase the likelihood of finding angiographic stenosis. ${ }^{3}$ The results of our study further suggests that there is a better chance of finding operable carotid stenosis in patients with TIAs lasting no more than an hour.
This may be helpful in selecting patients for angiography. Paradoxically, the patient with the more obtrusive and symptomatically worrying long attack is less likely to have an operable lesion on investigation.

\section{References}

1 Ross Russell, R W, Lancet, 1961, 2, 1422.

2 Harrison, M J G, in Tenth Symposium on Advanced Medicine. London, Pitman, 1974.

${ }^{3}$ Harrison, M J G, and Marshall, J, British Medical fournal, 1975, 1, 616.

4 Toole, J F, et al, Archives of Neurology, 1975, 32, 5.

5 Pickering, G W, High Blood Pressure, 2nd edn. London, J and A Churchill, 1968.

${ }^{6}$ Pessin, M S, et al, New England fournal of Medicine, 1977, 296, 358.

${ }^{7}$ Harrison, M J G, and Marshall, J, British Fournal of Surgery, 1977, 64, 511.

${ }^{8}$ Marshall, J, and Wilkinson, I M S, Brain, 1971, 94, 395.

\title{
Sjögren's syndrome treated with bromhexine: a randomised clinical study
}

\author{
K FROST-LARSEN, H ISAGER, R MANTHORPE
}

\section{Summary and conclusions}

Existing treatment for Sjögren's syndrome is unsatisfactory, and uncontrolled observations have suggested that bromhexine may be effective. Twenty-nine patients with Sjögren's syndrome were therefore assigned to two randomised double-blind crossover trials with bromhexine and placebo, each comprising two two-week periods. In the first trial bromhexine $24 \mathrm{mg} /$ day was given by mouth; in the second the dose was increased to 48 mg/day. After each treatment period the Schirmer test response, break-up time, Bijsterveld score, and the time taken for the patient to eat a dry biscuit were recorded, as well as the patient's estimate of moistness in the eyes and mouth.

In the second (higher-dose) trial values on the Schirmer test were significantly higher after bromhexine than after placebo and the break-up time was also increased after bromhexine, which suggested that the drug has a dose-dependent effect on lacrimal gland secretion in Sjögren's syndrome. It had no effect on salivary gland function.

Bromhexine is therefore valuable in the treatment of Sjögren's syndrome.

\section{Introduction}

Treatment of Sjögren's syndrome is unsatisfactory, and some of the drugs used-for example, immunosuppressive agents-

\section{Gentofte Hospital, DK 2900 Hellerup, Denmark}

K FROST-LARSEN, MD, clinical assistant, eye department

Rigshospitalet, Tagensvej, DK 2200 Copenhagen N, Denmark

$H$ ISAGER, MD, PHD, department of infectious diseases $M$

R MANTHORPE, MD, medical department TA produce side effects out of proportion to the chronic and usually benign course of the disease. ${ }^{2}$ The dry eyes of Sjögren's syndrome (keratoconjunctivitis sicca) are usually treated topically with tear substitutes or soft contact lenses, or both, but the ocular complaints are rarely relieved.

We recently observed an apparently complete remission of dryness of the eyes and mouth in a patient with Sjögren's syndrome who had been given bromhexine (Bisolvon) for dry bronchitis. The dryness recurred when the drug was discontinued and disappeared again when it was resumed; the Schirmer test responses showed the same pattern. ${ }^{3}$ Other uncontrolled observations also support the alleviating value of bromhexine in these cases. ${ }^{45}$

Bromhexine has been used for treating chronic bronchitis for the past decade. Clinical studies have shown that it increases the quantity of bronchial secretion and reduces its viscosity, but its mechanism of action is not fully known. Reported side effects have been harmless and infrequent. ${ }^{6}$

Our aim was to determine whether any differences could be shown in the effect on lacrimal and salivary gland secretion between bromhexine and placebo in patients with Sjögren's syndrome.

\section{Patients and methods}

Two trials (of low and high doses), both of double-blind crossover design, were carried out consecutively. Each trial comprised two twoweek periods, and balanced numbers of patients were randomly allocated for treatment with bromhexine in one of the periods and with placebo tablets of identical appearance in the other. The dose of bromhexine in trial 1 was $8 \mathrm{mg}$ three times daily by mouth; this dose was doubled in trial 2 (16 mg three times daily). The doses of other drugs being administered were kept constant throughout the trials. The patients were seen every two weeks, when their tablets were counted and a new supply issued. The variables described below were measured at the same time. The ophthalmological variables (in both eyes) were checked by one of us (KF-L).

The criterion for including a patient with Sjögren's syndrome in the trial was a Schirmer test result of less than $10 \mathrm{~mm}$ in both eyes on two consecutive occasions. Thirty-one of our patients fulfilled this criterion. After an oral and written explanation of the purpose and 